\title{
Microbial Degradation of Corrinoids
}

\author{
VI. Reduction of Hydroxocobalamin by Cell-free \\ Particles from Pseudomonas rubescens
}

\author{
J. B. HUFHAM, ${ }^{1}$ R. C. BURGUS, ${ }^{2}$ SANDRA Y. S. ING, AND J. J. PFIFFNER \\ Department of Physiology and Pharmacology, Wayne State University School of Medicine, \\ Detroit, Michigan 48207
}

Received for publication 14 December 1967

\begin{abstract}
Cell-free particles from Pseudomonas rubescens have been shown to reduce hydroxocobalamin to vitamin $\mathbf{B}_{12 \mathrm{r}}$. The particles are unable to reduce the $\mathbf{B}_{12 \mathrm{r}}$ to $\mathbf{B}_{12 \mathrm{~s}}$. The reduction of hydroxocobalamin is dependent upon reduced nicotinamide adenine dinucleotide and is stimulated by flavin adenine dinucleotide. Cobinamide and diaquocobinamide were reduced at 25 and $10 \%$, respectively, of the rate of hydroxocobalamin. Cyanocobalamin, coenzyme $\mathbf{B}_{12}$, pseudovitamin $\mathbf{B}_{12}$, and diaquopseudocobalamin were not reduced. Reduced nicotinamide adenine dinucleotide phosphate and flavin mononucleotide were not active. Diaphorase and xanthine oxidase activity were not present in the particulate fraction.
\end{abstract}

In a preliminary report (4), we described the reduction of hydroxocobalamin by whole cells of Pseudomonas rubescens. The importance of this reaction, wherein the trivalent cobalt in hydroxocobalamin is reduced to the bivalent cobalt of vitamin $B_{12 r}$, is shown by the results obtained in studies concerned with other reactions in which vitamin $\mathbf{B}_{12}$ is involved. Takeyama and Buchanan (9), working with a $B_{12}$-enzyme complex which incorporates the methyl group into methionine, found that the vitamin must be reduced before it can combine with the apoenzyme moiety to form the holoenzyme. More recently, Weissbach et al. (12) showed that, owing to the absence of a carbon-to-cobalt bond in the hydroxocobalamin, reduction is necessary for the formation of the holoenzyme. Brady and Barker (1) demonstrated that reducing conditions are also necessary for the formation of cobamide coenzyme from hydroxocobalamin; this was later confirmed by Weissbach et al. (11).

Vitols, Walker, and Huennekens (10) were able to purify an adenosylating enzyme responsible for adding the adenosyl group to the cobalt of vitamin $\mathbf{B}_{12 \mathrm{~s}}$. They reported that this enzyme does not utilize vitamin $B_{12 r}$ or hydroxocobalamin and they showed that the overall reaction in the conversion of $B_{12}$ to coenzyme is the summation

\footnotetext{
${ }^{1}$ Present address: Space Defense Corp., Birmingham, Mich. 48011.

2 Present address: Department of Physiology, Baylor University College of Medicine, Houston, Tex. 77025.
}

of two separate and distinct reactions involving different enzymes:

$$
\begin{gathered}
\text { hydroxocobalamin }+2[\mathrm{H}] \rightarrow \mathbf{B}_{12 \mathrm{~s}} \\
\mathbf{B}_{12 \mathrm{~s}}+\mathrm{ATP} \rightarrow \text { adenosyl } \mathbf{B}_{12}+\mathbf{P P P}_{\mathrm{i}}
\end{gathered}
$$

Studies concerned with the degradation of vitamin $\mathbf{B}_{12}$ have also shown that a reduced form of the vitamin is a necessary intermediate in the ultimate breakdown of the molecule $(2,8)$. This reduction reaction, therefore, seems to be common to several pathways in the metabolism of vitamin $\mathbf{B}_{12}$. Reaction 1 , as written, shows the vitamin being reduced to the $B_{12 s}$ oxidation state and implies that this is a one-step reaction brought about by a single cobalamin reductase. In previous work, we studied this reaction only as far as the formation of $B_{12 \mathrm{r}}$ from hydroxocobalamin and its implications in the overall catabolism of the vitamin by microorganisms. With the role of $\mathbf{B}_{12 \mathrm{~s}}$ gaining more importance as an intermediate in the metabolism of vitamin $\mathbf{B}_{12}$, the cobalamin reduction system of $P$. rubescens has been examined for its ability to reduce hydroxocobalamin to the oxidation state of vitamin $\mathbf{B}_{12 \mathrm{~s}}$.

Our preliminary work indicated that the enzyme involved in this reduction was simply a "diaphorase." Since a natural electron acceptor for this group of enzymes has never been isolated, it was necessary to study the system with respect to diaphorase activity. Xanthine oxidase activity was also investigated, since this enzyme can also oxidize reduced nicotinamide adenine dinucleo- 
tide $\left(\mathrm{NADH}_{2}\right)$ in the presence of flavin adenine dinucleotide (FAD).

The present paper describes the preparation of a cell-free, particulate cobalamin reducing system from $P$. rubescens. The system was studied with respect to its substrate specificity, cofactor requirements, and the oxidation state of the reduction product formed in the reaction.

\section{Materials AND Methods}

Cultural. The original culture of $P$. rubescens (ATCC 12099) was obtained from the American Type Culture Collection. It was maintained on Stock Culture Agar (Difco) with frequent transfers and with storage at $4 \mathrm{C}$.

The cells were grown in a 14-liter fermentation apparatus (New Brunswick Scientific Co., New Brunswick, N. J.) which contained 7 liters of Nutrient Broth (Difco) with $1.0 \%$ glucose. The cultures were vigorously aerated for $16 \mathrm{hr}$ at $30 \mathrm{C}$ and were harvested by means of a refrigerated, continuous-flow centrifuge (Ivan Sorvall Inc., Norwalk, Conn.). The cells were resuspended in cold $0.9 \%$ sodium chloride and recentrifuged. The cell paste was then frozen and stored at $-20 \mathrm{C}$ until needed.

Substrates. Vitamin $\mathrm{B}_{12}$ and hydroxocobalamin, were generously supplied by Merck \& Co., Inc., Rahway, N. J. Pseudovitamin $B_{12}$ was isolated from natural sources (3), and coenzyme $B_{12}$ was obtained from E. R. Squibb \& Sons, New York, N.Y.

Cobinamide (factor B) was prepared by the hydrolysis of vitamin $B_{12}$ with perchloric acid. The $B_{12}(100$ $\mathrm{mg}$, dry weight) was treated with $3.5 \mathrm{ml}$ of $70 \%$ perchloric acid at $65 \mathrm{C}$ for $5 \mathrm{~min}$. After cooling to $0 \mathrm{C}$, the solution was neutralized with $1 \mathrm{~N} \mathrm{KOH}$ and filtered. The filtrate was evaporated to dryness in vacuo at $50 \mathrm{C}$, and the resulting residue was dissolved in $4.0 \mathrm{ml}$ of water and diluted with $10 \mathrm{ml}$ of isopropanol. After being cooled to $0 \mathrm{C}$ and refiltered, the solution was evaporated to dryness. The residue was dissolved in $5.0 \mathrm{ml}$ of water and applied to a carboxymethylcellulose column $(2 \times 26 \mathrm{~cm})$ which had been prewashed with $1 \mathrm{~N}$ acetic acid and water. The column was washed with water, to remove the unreacted material, and the cobinamide was then eluted with $0.05 \mathrm{M}$ acetic acid and lyophilized. The total yield was $48 \mathrm{mg}$.

Diaquocobinamide (hydroxo factor B) and diaquopseudocobalamin were prepared by photolysis of the cobinamide and pseudocobalamin in acid solution. A solution containing $5 \mathrm{mg}$ of the proper corrinoid in $100 \mathrm{ml}$ of $10^{-2} \mathrm{~N}$ acetic acid was exposed to two 300-w floodlamps. The temperature of the reaction vessel was maintained at 19 to $21 \mathrm{C}$ by means of a circulating water bath, and the solution was vigorously agitated by bubbling with nitrogen. After $30 \mathrm{~min}$, there was no further change noted in the spectrum of the reacting solution. The preparation was concentrated to dryness in vacuo at $45 \mathrm{C}$, and the residue was dissolved in 5.0 $\mathrm{ml}$ of water.

Methyl cobalamin (methyl coenzyme $\mathbf{B}_{12}$ ) was prepared by the method of Johnson et al. (5). Oxygenfree nitrogen, prepared by flowing commercial nitro- gen over copper turnings at $450 \mathrm{C}$, was bubbled through a solution containing $25 \mathrm{mg}$ of hydroxocobalamin in $15 \mathrm{ml}$ of aqueous methanol $(1: 1, \mathrm{v} / \mathrm{v})$ for 1 $\mathrm{hr}$. While working under a stream of nitrogen and under subdued light, we added $8.0 \mathrm{ml}$ of gassed ethyl alcohol containing $8.0 \mathrm{mg}$ of sodium borohydride. When the color had faded (10 to $15 \mathrm{~min}$ ), $1.2 \mathrm{ml}$ of a $1.0 \%(\mathrm{v} / \mathrm{v})$ solution of methyl iodide (Distillation Products Industries, Rochester, N.Y.) in ethyl alcohol was added and, after $30 \mathrm{~min}$, the preparation was dried in vacuo. The residue was dissolved in $10 \mathrm{ml}$ of water and extracted with a 1:1 (v/v) phenol-chloroform solution. After being washed with water, the pigment was re-extracted into a small amount of water by adding 1 volume of ether. The aqueous layer was washed with ether, and the methyl cobalamin was crystallized by the addition of acetone. The total yield was $17.6 \mathrm{mg}$.

Preparation of particles. To prepare the cell-free particles, the cells were first converted to protoplastlike bodies (by use of lysozyme), and the soluble, contaminating materials were removed by washing with buffer. A 20-g amount (wet weight) of cell paste was suspended in $150 \mathrm{ml}$ of $0.1 \mathrm{M}$ tris(hydroxymethyl)aminomethane (Tris) buffer, $p \mathrm{H} 8.0$, and $10 \mathrm{mg}$ of lysozyme and $10 \mathrm{mg}$ of disodium ethylenediaminetetraacetate (EDTA) were added with stirring. After several minutes, the solution became highly viscous. The viscosity was reduced by bringing the solution to $0.05 \mathrm{M}$ with $\mathrm{MgSO}_{4}$. The addition of $20 \mu \mathrm{g}$ of deoxyribonuclease removed the remaining viscosity. The stirring was continued for $30 \mathrm{~min}$ at room temperature. Microscopic examination, at this point, showed more than $95 \%$ spherical forms; further incubation did not result in better yields. The solution $(190 \mathrm{ml})$ was centrifuged at $10,000 \times g$ for $30 \mathrm{~min}$ at $4 \mathrm{C}$, and the supernatant fraction $(175 \mathrm{ml})$ was removed (first washing, see Table 1). The sediment was

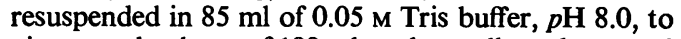
give a total volume of $100 \mathrm{ml}$, and was allowed to stand overnight at $4 \mathrm{C}$. The suspension was again centrifuged at $10,000 \times g$ for $30 \mathrm{~min}$, and the supernatant washing was removed (second washing). The sediment, which contained all of the enzyme activity, was resuspended

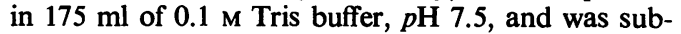
jected to sonic disruption (Branson Sonifier) for 30 sec while being kept cold in an ice-salt bath. The resulting solution was centrifuged at 7,000 $\times g$ for 10 min to remove the cellular debris, and the supernatant solution was then centrifuged at $35,000 \times g$ for $1 \mathrm{hr}$ to sediment the particulate matter which contained the enzyme activity.

Assay system. The reducing activity was assayed anaerobically by use of Thunberg cuvettes (Arthur $\mathbf{H}$. Thomas Co., Philadelphia, Pa.) and an atmosphere of nitrogen. The reaction mixture contained, in $3.0 \mathrm{ml}$ : Tris buffer, $p \mathrm{H} 7.5,100 \mu$ moles; $\mathrm{NADH}_{2}, 400 \mathrm{~m} \mu$ moles; hydroxocobalamin, $300 \mathrm{~m} \mu$ moles; and enzyme, 10 to 50 units. The Thunberg cuvette was evacuated three times by use of a vacuum pump (Leybold, model 25) and was refilled each time with commercial nitrogen. A slight positive pressure was added to prevent the leakage of air into the cuvette. The reaction was started by the addition of the $\mathrm{NADH}_{2}$ solution from 
the side arm, and the change in optical density at 528 $\mathrm{m} \mu$ was determined in a Beckman DB spectrophotometer and recorded on a Sargent SRL recorder. A unit of enzyme activity was defined as that amount which caused a decrease in optical density of 0.001 per minute under these conditions.

Determination of $B_{12 s}$. To determine whether the system could reduce hydroxocobalamin to $B_{12 s}$, it was necessary to remove all traces of oxygen from the reaction vessel. For this experiment, the commercial nitrogen was purified by passing it over copper turnings heated to $450 \mathrm{C}$. The reaction was carried out in the same manner as given previously for the assay system, with the exception that the concentrations of the reactants were doubled and they were all added to the cuvette before the initial evacuation. After the third filling with nitrogen, the cuvette was opened, and $0.1 \mathrm{ml}$ of a solution of ${ }^{14} \mathrm{CH}_{3} \mathrm{I}$, containing $5 \mu \mathrm{C}$ $(0.35 \mathrm{mg})$ in methanol, which had been gassed with nitrogen, was quickly added to the side arm. The cuvette was then evacuated and filled with nitrogen. After incubation for $30 \mathrm{~min}$ at room temperature (and under subdued light), the methyl iodide solution was added to the main compartment and allowed to react for $30 \mathrm{~min}$. The mixture was concentrated in vacuo and applied to Whatman no. 1 paper strips $(1 \times 34.5$ $\mathrm{cm})$. Electrophoresis was carried out in $1 \mathrm{~N}$ acetic acid for $2.5 \mathrm{hr}$ at $500 \mathrm{v}(1.25 \mathrm{ma})$. A control strip containing hydroxocobalamin, vitamin $B_{12}$, and methylcobalamin was included. The area corresponding to the control methylcobalamin was cut out, eluted with water, and dried in a planchet. Radioactivity was determined by use of a proportional counter (Baird Atomic).

Diaphorase activity. The various fractions, obtained while purifying the particles, were examined for the presence of "diaphorase activity." Both 2,6 dichlorophenol-indophenol and potassium ferricyanide were employed as electron acceptors (7). Xanthine oxidase activity was examined by the conversion of hypoxanthine to uric acid (6).

Materials. Lysozyme, EDTA, reduced nicotinamide adenine dinucleotide phosphate $\left(\mathrm{NADPH}_{2}\right)$, and FAD were purchased from Sigma Chemical Co., St. Louis, Mo. Deoxyribonuclease and nicotinamide adenine dinucleotide (NAD) were purchased from Worthington Biochemical Co., Freehold, N.J. Flavin mononucleotide (FMN) was obtained from Calbiochem, Los Angeles, Calif. $\mathrm{NADH}_{2}$ was obtained from both Calbiochem and Worthington. Methyl iodide $\left.{ }^{14} \mathrm{CH}_{8} \mathrm{I}\right)$ was purchased from New England Nuclear Corp., Boston, Mass.

\section{RESULTS}

Particle preparation. The enzyme system responsible for the reduction of hydroxocobalamin to $\mathrm{B}_{12 \mathrm{r}}$ by cultures of $P$. rubescens was found to be loosely bound to a cell particle. Long periods of sonic disruption tended to solubilize the enzyme system, leading to decreased activity and perhaps denaturation. The particles were sedimented by centrifugation at 35,000 $\times g$ for $1 \mathrm{hr}$ and were dark red in color. Most of the activity remained in this particulate fraction, although some appeared in the supernatant solution, either as unsedimentable particles or as solubilized enzyme.

Table 1 shows the distribution of activity in each of the fractions during the isolation procedure. The lysozyme extracts contained no activity. The particulate fraction showed an increase of only $10 \%$, whereas the soluble enzyme activity increased more than $100 \%$ with the addition of FAD to the reaction mixture.

Cofactors. The reducing system, alone, was inactive when incubated with hydroxocobalamin (Table 2). $\mathrm{NADH}_{2}$ was found to reduce the vitamin slowly, and this activity had to be corrected for in the assay of the reducing system. The addition of FAD caused a slight stimulation of the nonenzymatic reduction of hydroxocobalamin by $\mathrm{NADH}_{2}$.

$\mathrm{NADPH}_{2}$ was examined to see whether it could also act as an electron donor in the reduction. Although it displayed a nonenzymatic reduction of the vitamin almost as great as that caused by $\mathrm{NADH}_{2}$, the rate was not increased by the addition of the particles. The addition of FAD had no effect when $\mathrm{NADPH}_{2}$ was used. FMN was also

TABLE 1. Fractionation of the cobalamin reducing system

\begin{tabular}{|c|c|c|}
\hline \multirow{2}{*}{ Fraction } & \multicolumn{2}{|c|}{ Total units } \\
\hline & No FAD & $\begin{array}{l}\text { With FAD } \\
\text { (200 m } \mu \text { moles) }\end{array}$ \\
\hline $\begin{array}{l}\text { First washing } \ldots \ldots \ldots \\
\text { Second washing. ...... } \\
\text { High-speed sediment } \\
\text { High-speed superna- } \\
\quad \text { tant fraction. . . . }\end{array}$ & $\begin{array}{c}0 \\
0 \\
406 \stackrel{103}{\times 10^{3}} \\
52.5 \times 10^{3}\end{array}$ & $\begin{array}{l}0 \\
\stackrel{0}{ } \\
456 \times 10^{3} \\
118 \times 10^{3}\end{array}$ \\
\hline
\end{tabular}

a Sediment was obtained by centrifugation at $35,000 \times g$ for $1 \mathrm{hr}$.

TABLE 2. Cofactor requirements for reducing activity by particles from Pseudomonas rubescens

\begin{tabular}{|c|c|}
\hline Additions $^{a}$ & Activity \\
\hline Enzyme, FAD. . & 0 \\
\hline $\mathbf{N A D H}_{2} \ldots \ldots$ & 20 \\
\hline $\mathrm{NADH}_{2}$, FAD $\ldots$ & 26 \\
\hline Enzyme, $\mathrm{NADH}_{2}$. & 155 \\
\hline Enzyme, FAD, $\mathrm{NADH}_{2} \ldots$ & 173 \\
\hline Enzyme, FAD, $\mathrm{NADPH}_{2} \ldots \ldots$ & 18 \\
\hline Enzyme, FMN, $\mathrm{NADH}_{2} \ldots \ldots \ldots$ & 20 \\
\hline
\end{tabular}

${ }^{a}$ The assay mixture contained buffer and hydroxocobalamin in addition to the above cofactors. 
tried in an attempt to replace FAD and was found to be completely inactive.

Vitamin $B_{12}$ analogues. The activity of the reducing system for certain vitamin $\mathbf{B}_{12}$ analogues is shown in Table 3. Of those compounds studied, none was as active as hydroxocobalamin. Cobinamide (factor B) gave $25 \%$ and diaquocobinamide gave $10 \%$ as much activity as hydroxocobalamin. Vitamin $\mathbf{B}_{12}$, pseudovitamin $\mathbf{B}_{12}$, diaquopseudovitamin $\mathbf{B}_{12}$, and coenzyme $\mathbf{B}_{12}$ were inactive.

Final reduction state. To determine whether vitamin $\mathbf{B}_{12 \mathrm{~s}}$ was formed as the final product in the reduction, the reaction of methyl iodide with $B_{12 s}$, to form methyl cobalamin, was employed. $B_{12 r}$ cannot be methylated in this reaction and would be oxidized to hydroxocobalamin following the aeration used in the analysis of the compounds. Methyl cobalamin, however, is not affected by aeration as long as light is excluded.

Precautions were taken to insure the complete removal of all oxygen from the system. The reaction was tested several times with the use of borohydride in place of enzyme. This was done to be sure that any $B_{12 s}$ formed could be converted and isolated as its methyl derivative. ${ }^{14} \mathrm{CH}_{3} \mathrm{I}$ was employed so that trace quantities of $B_{12 s}$, if formed, could be detected. Since methyl cobalamin was never found under these conditions, it was concluded that the final reduction product is $B_{12 r}$, not $B_{12 s}$.

Diaphorase. $P$. rubescens contains a highly active diaphorase. Examination of the various fractions showed that it was almost totally removed in the two washings (Table 1) and the high-speed supernatant fraction contained only a trace of activity. The particles themselves had no diaphorase activity. No xanthine oxidase activity was found in any of the fractions.

\section{Discussion}

The data obtained in the present investigation support the reaction scheme shown in Fig. 1. The fact that hydroxocobalamin differs from

TABLE 3. Reduction of various vitamin $B_{12}$ analogues by the particulate system of Pseudomonas rubescens

Substrate Relative activity

Hydroxocobalamin . . . . . . . . . $\quad 100$

Cobinamide. ................ 25

Diaquocobinamide . . . . . . . . . 10

Vitamin $\mathbf{B}_{12} \ldots \ldots \ldots \ldots \ldots \ldots \ldots$

Pseudovitamin $\mathrm{B}_{12} \ldots \ldots \ldots \ldots \ldots \ldots$

Coenzyme $B_{12} \ldots \ldots \ldots \ldots \ldots$

Diaquopseudovitamin $\mathbf{B}_{12} \ldots \ldots \ldots$.

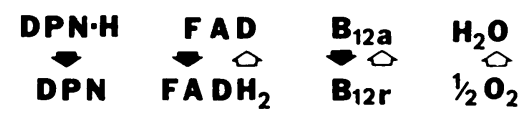

Fig. 1. Proposed reaction scheme for the reduction of hydroxocobalamin and its auto-oxidation in the presence of air. (DPN and DPN.H represent nicotinamide adenine dinucleotide and its reduced form; FAD and $\mathrm{FADH}_{2}$ represent flavin adenine dinucleotide and its reduced form.

vitamin $B_{12}$ by loss of the cyano-group and that $B_{12}$ was not utilized indicated that the $C N$ group interfered. For this reason, the diaquo forms of both cobinamide (which gave some activity) and pseudocobalamin were tested. Although it was expected that diaquopseudocobalamin might be inactive, owing to its adenine base moiety, it was thought that the diaquocobinamide would result in some increase in activity. Such was not the case, however; the activity was less than half that of the cyano derivative.

The fact that $B_{12 r}$ can react with molecular oxygen does not mean that this reaction takes place in vivo. The importance of the physical arrangement of the oxidation-reduction components of the cell might interfere with the direct participation of such a reaction, and the electron transfer may still be by way of the cytochrome system. It is interesting that in previous studies (4) we found the lack of such a reducing system in several anaerobic bacteria (i.e., Propionibacterium, Clostridium). In those studies, however, whole cells were used, and the negative results might be attributable to a permeability factor rather than to the lack of the reducing system itself.

Even though bacteria are poor sources of xanthine oxidase, the fact that reducing compounds such as reduced FAD, NAD, and lipoic acid are capable of reducing $B_{12}$ made it necessary to determine whether this enzyme was present, since its diaphorase activity could be generating enough reduced FAD to bring about a chemical reaction. As was expected, no xanthine oxidase activity was found in $P$. rubescens.

The diaphorase activity present in $P$. rubescens can easily be separated from the particulate reducing system. The diaphorase is soluble and is washed from the cell during the lysozyme extraction. Since there is no correlation between the fractionation of the diaphorase and the $B_{12}$ reductase, they would appear to be two separate enzymes.

The presence of vitamin $B_{12}$, and of a system capable of reducing it to $B_{12 r}$, in the cytochromecontaining fractions of the cell causes speculation 
on the role of this vitamin in cellular metabolism. The ease with which it is oxidized and reduced and its use as an oxido-reductant in several key reactions within the cell seem to point to a coupling between the cytochrome system and the noncytochrome oxidation-reductions being carried on throughout the cell.

\section{ACKNOWLEDGMENT}

This investigation was supported by Public Health Service grant AM (04302) from the National Institute of Arthritis and Metabolic Diseases.

\section{Literature Cited}

1. Brady, R. O., and H. A. Barker. 1961. The enzymatic synthesis of cobamide coenzymes. Biochem. Biophys. Res. Commun. 4:464-468.

2. Burgus, R. C., J. B. Hufham, W. M. ScotT, AND J. J. PfiffNer. 1964. Microbial degradation of corrinoids. III. Pigments derived from vitamin $\mathrm{B}_{12}$ by Pseudomonas rubescens. J. Bacteriol. 88:1139-1144.

3. Dion, H. W., D. G. Calkins, and J. J. Pfiffner. 1952. Hydrolysis products of pseudovitamin $B_{12}$. J. Am. Chem. Soc. 74:1108-1112.

4. Hufham, J. B., R. C. Burgus, W. M. ScotT, AND J. J. Pfiffner. 1964. Reduction of vitamin $\mathbf{B}_{12}$ by Pseudomonas rubescens. J. Bacteriol. 88: 538-540.

5. Johnson, A. W., L. Mervyn, N. Shaw, and E. L. Smith. 1963. A partial synthesis of the vitamin $B_{12}$ coenzyme and some of its analogs. J. Chem. Soc., p. 4146-4156.

6. KalcKaR, H. M. 1947. Differential spectrophotometry of purine compounds by means of specific enzymes. I. Determination of hydroxypurine compounds. J. Biol. Chem. 167:429-443.

7. Mahler, H. R. 1955. Diaphorases, p. 707-711. In S. P. Colowick and N. O. Kaplan [ed.], Methods in enzymology, vol. 2. Academic Press, Inc., New York.

8. Scott, W. M., R. C. Burgus, J. B. Hufham, AND J. J. PfiffNer. 1964. Microbial degradation of corrinoids. I. Vitamin $\mathbf{B}_{12}$. J. Bacteriol. 88: 581-585.

9. Takeyama, S., AND J. M. Buchanan. 1961. Enzymatic synthesis of the methyl group of methionine. III. Spectral and electrophoretic studies of the prosthetic group of the $B_{12}$ enzyme. J. Biochem. (Tokyo) 49:578-588.

10. Vitols, E., G. A. WALker, AND F. M. HuEnNeKENS. 1966. Enzymatic conversion of vitamin $B_{12 s}$ to a cobamide coenzyme, $\alpha$-(5,6-dimmethylbenzimidazolyl) deoxyadenosylcobamide (adenosyl-B ${ }_{12}$ ). J. Biol. Chem. 241:1455-1461.

11. Weissbach, H., B. G. Redfield, and A. PeterKOFSKY. 1962. Biosynthesis of $B_{12}$ coenzyme: requirements for release of cyanide and spectral changes. J. Biol. Chem. 237:3217-3222.

12. Weissbach, H., B. G. Redfield, H. Dickerman, AND N. BRot. 1964. Studies on methionine biosynthesis: effect of alkylcobamide derivatives on the formation of holoenzyme. J. Biol. Chem. 240:856-862. 